\title{
Perspectivas das infraestruturas: organização, conhecimento e poder
}

Jean Carlos Hochsprung Miguel ${ }^{1}$

\section{Resumo}

Nas últimas décadas, o tema das infraestruturas adquiriu grande relevância na área dos Estudos Sociais da Ciência e da Tecnologia (ESCT) e da Antropologia da Ciência e da Tecnologia (ACT), dentre outras áreas. A maneira que a vida moderna tem acontecido entrelaçada aos sistemas técnicos, fez com que o foco da análise social fosse dirigido às infraestruturas, resultando em um renovado número de questões e abordagens sobre as formas de organização social, a produção do conhecimento e o exercício do poder. Nesse texto, apresento uma perspectiva analítica sobre as infraestruturas, sugerindo que essa é uma forma produtiva e inovadora de pensar temas e questões prementes da sociedade moderna.

Palavras-chave: Infraestruturas; Estudos Sociais da Ciência e da Tecnologia; Antropologia da Ciência e da Tecnologia; Tecnopolítica; Social Studies of Science.

\footnotetext{
${ }^{1}$ Pesquisador de Pós-doutorado na Escola de Filosofia, Letras e Ciências Humanas da Universidade Federal de São Paulo (UNIFESP).
} 


\section{O que é uma infraestrutura?}

O termo "infraestrutura", familiar a tantos profissionais, dentre eles, engenheiros, tecnólogos, arquitetos, urbanistas..., mas também familiar aos cientistas sociais e filósofos, é um termo polissêmico. Requer, portanto, uma primeira definição de trabalho como ponto de partida para uma reflexão mais profunda. O dicionário de português da Google traz uma interessante definição do termo: "infraestrutura: suporte, escondido ou invisível, que é base indispensável à edificação, à manutenção ou ao funcionamento de uma estrutura concreta ou abstrata, visível ou percebida racionalmente". Esta definição já nos indica que se trata de um objeto cheio de sutilezas, pois se refere a algo que paira entre o concreto e o abstrato, que está, ao mesmo tempo, no domínio do visível e do invisível, que dá suporte e edifica, que faz funcionar...

De maneira imediata, o termo infraestrutura evoca em nosso imaginário a dureza do concreto e aço das edificações urbanas, os fios e componentes eletrônicos, as linhas de trem, dentre outros componentes e plataformas que dão suporte às nossas ações. $\mathrm{O}$ historiador da ciência e da tecnologia Paul Edwards (2003) nos diz que o termo "infraestruturas" foi originalmente utilizado no meio militar para designar "instalações fixas", bases sobre as quais as organizações sociais operam, por exemplo: rodovias, sistemas de abastecimento de água, redes elétricas, sistemas de esgoto etc. Contudo, se pensarmos nos atuais fluxos de informações que acontecem através da internet, percebemos que as infraestruturas podem ser fluidas e intangíveis, tornando-se um objeto de estudo desafiador.

Nas Ciências Sociais, especialmente nos estudos marxistas e na formulação dada por Louis Althusser (1970, p.26), o termo infraestrutura surge como categoria analítica para explicar a composição da estrutura de toda a sociedade. A sociedade, metaforicamente representada por Althusser como "um edifício que comporta uma base (infraestrutura) sobre a qual se erguem outros andares (superestrutura)", é imaginada como uma sobreposição de camadas. Uma primeira camada, a das infraestruturas, se refere aos instrumentos de produção, trabalho, relações técnicas e sociais de trabalho. A segunda camada, a das superestruturas, se refere à religião, à família, ao Estado, ao direito, à moral, à ciência etc. Nesse sentido, a base material da sociedade (infraestrutura) que, segundo Marx 
e Engels (2001), determina suas formas ideológicas (superestrutura) formam o modo de produção de uma determinada época.

Para além dos estudos marxistas, tanto o termo infraestrutura quanto "estrutura" 2 são usados nas Ciências Sociais para se referir a algo que não está visível, que não é óbvio, mas que determina certas formas de organização econômica e política; condiciona comportamentos e dispõe certos modos de organização social. Representar e refletir a respeito dessas (infra)estruturas tem sido objeto de estudo de inúmeros estudos sociais que as consideram como sendo de caráter dinâmico no processo de organização das sociedades.

Nas últimas décadas, o termo infraestruturas passou a ser reinterpretado ao se estudar aquelas infraestruturas comumente reconhecidas como sendo a base material sobre as quais as organizações sociais operam, exemplos: as rodovias, os sistemas de abastecimento de água, as redes elétricas, os sistemas de esgoto, internet etc. Tais infraestruturas se tornaram objetos de estudo cada vez mais relevantes para a pesquisa social, especialmente para investigadores ligados aos campos interdisciplinares dos Estudos Sociais da Ciência e da Tecnologia (ESCT) ${ }^{3}$ e da Antropologia da Ciência e da Tecnologia $(\mathrm{ACT})^{4}$. As elaborações teóricas e estudos empíricos alcançaram um volume bastante expressivo de produções que, em seu conjunto, formaram uma linha de estudos chamada, em língua inglesa, de Infrastructure Studies (EDWARDS, et al, 2009).

Estes estudos de infraestruturas partem do diagnóstico de que viver no mundo moderno é viver por meio e na presença de infraestruturas. Esse aspecto da modernidade nos parece evidente na atualidade quando a maior parte da população mundial vive em cidades e depende de um incontável número de sistemas técnicos para se locomover, trabalhar, se alimentar e se comunicar. As infraestruturas parecem estar por toda parte,

\footnotetext{
2 Vide a corrente do "estruturalismo" e sua influência no desenvolvimento do pensamento social. Teoria cuja formação e influência podem ser vistas tanto nos campos da linguística (Ferdinand de Saussure), literatura (Roland Barthes), psicanálise (Jacques Lacan), história (Fernand Braudel), antropologia (Claude Lévi-Strauss) e filosofia (Louis Althusser) como pode na sociologia. Está associada à busca por estruturas profundas e relativamente duradouras que estão abaixo do fluxo e da mudança de eventos superficiais e contingências aparentes. Em sociologia, a obra de Émile Durkheim e Marcel Mauss é frequentemente associada ao estruturalismo, assim como a obra de escritores posteriores como Pierre Bourdieu, Anthony Giddens e Stuart Hall, todos claramente marcados pela tradição.

${ }^{3}$ Estudos cujo ponto de partida está no entendimento de que ciência e tecnologia são atividades sociais, situadas no tempo, no espaço, na cultura, sendo, portanto, impossível compreendê-las separadamente da sociedade. Para uma introdução às principais teorias e temas desse campo vide: Sismondo (2010).

4 Área de estudo que se destaca dos tradicionais ESCT por adentrar de maneira mais profunda o estudo do humano na modernidade, atacando as tradicionais clivagens entre natureza e cultura, corpo e ambiente, humano e não-humano. Ver: Fonseca et al (2019).
} 
como uma "segunda natureza" (BOWKER, 1995), a qual habitamos, nos relacionamos, através da qual pensamos e agimos no tempo e no espaço. Portanto, o reconhecimento do seu papel constitutivo da modernidade, sua inegável presença nas formas de organização e controle social, e seu envolvimento no modo em que nós significamos o mundo, fez com que o estudo das infraestruturas interessasse não só às engenharias, mas também às humanidades.

Autores dos ESCT tratam do tema da tecnologia e das relações entre a sociedade e os sistemas técnicos desde os primórdios desse campo na década de 1980 (HUGHES, 1983; WINNER, 1986; BIJKER, et al 1987). Não obstante, elaborações teóricas e pesquisas empíricas dirigidas especificamente ao tema das infraestruturas surgiram de maneira mais organizada em meados da década de 1990. Bowker, (1995), Star e Ruhleder (1996) foram alguns dos autores (as) que primeiro encararam o desafio de dar uma nova elaboração teórica às infraestruturas. Estes (as) autores (as) buscaram entender como as organizações e seus sistemas de informação ganham escala, coordenação e regularidade por longo período e através do espaço. Sua intuição era de que não seriam apenas aspectos ditos "sociais"5 que explicariam essa regularidade, mas também a circulação de referências, artefatos, padrões, dentre outras formas materiais e representacionais empregadas para regularizar determinadas práticas. Profundamente influenciados pelos trabalhos da Teoria Ator-Rede (TAR) ${ }^{6}$, estes (as) autores (as) consideraram que a materialidade das infraestruturas, a heterogeneidade dos atores que as compõem e suas formas de se associar e agir deveriam ser levados em conta para que as infraestruturas pudessem ser compreendidas para além de seus aspectos técnicos e sociais separadamente. O objetivo seria, por um lado, captar o caráter "sociotécnico" das infraestruturas, dando ênfase ao caráter relacional da tecnologia e da sociedade para escapar das armadilhas do determinismo tecnológico e do determinismo social.

\footnotetext{
${ }^{5}$ Os ESCT têm como uma de suas contribuições ao pensamento social enfatizar que o "social" não pode ser pensado como um tipo de material ou de domínio, questionando, assim, as tentativas de fornecer "explicações sociais" de outros estados de coisas sem que se leve em conta outros atores (não-humanos) que são mediadores daquilo que se chama de relação social. Os trabalhos do filósofo Bruno Latour (1986, 1991, 2012) e dos teóricos da Teoria Ator-Rede (TAR) representam a principal contribuição do campo para essa crítica.

${ }^{6}$ A TAR é caracterizada como uma vertente contestatória das abordagens tradicionais da Sociologia. Possui sua gênese nos Estudos Sociais da Ciência, Tecnologia. Mas deixou sua marca ao propor como forma de investigação da dinâmica de produção do conhecimento científico e tecnológico, considerar os atores humanos e os não-humanos nos processos de estabilização e difusão do conhecimento e da tecnologia. Os conceitos e preceitos dessa teoria estão detalhados em Latour (2012) dentre outros trabalhos.
} 
Bowker (1995) definiu como “inversão infraestrutural” (infrastructural inversion) a abordagem que descreve as infraestruturas não apenas como superfícies das quais os motivos sociais, culturais ou políticos podiam ser decodificados, mas como "uma segunda natureza", ou seja, como um conjunto de formas representacionais com as quais compreendemos e agimos no tempo e no espaço. Para Bowker (1995, p.48), dirigir o olhar às infraestruturas nos permite reconhecer estes "elos perdidos" entre a sociedade, a natureza (primeira natureza) e formas de representação do tempo e espaço (segunda natureza) que estão presentes nas organizações sociais.

Star e Ruhleder (1996, p.113), ao se perguntarem: “o que é uma infraestrutura?”, concluíram que as "infraestruturas são fundamentalmente relações e não uma coisa". Infraestruturas são articulações de materialidades com atores institucionais, regimes legais, políticas, práticas de conhecimento que estão em constante formação através do espaço e do tempo. O estudo das infraestruturas busca, portanto, compreender que tipo de relações configuram as infraestruturas, trazendo à luz a heterogeneidade de atores e os diferentes pontos de vista $^{7}$ e interesses que são articulados e incorporados nas dinâmicas infraestruturais.

Por exemplo, para um cozinheiro, o sistema de fornecimento de águas é uma infraestrutura de trabalho que lhe permite fazer o jantar. Sua percepção e interesse nessa infraestrutura não vai muito além de um meio que lhe proporciona o fornecimento contínuo da água. Para os planejadores urbanos e encanadores, o sistema de fornecimento de águas é uma variável de um complexo processo de planejamento e um objeto que requer constantes reparos. Portanto, definir o que é uma infraestrutura é uma questão de perspectiva e de relação (STAR, 1999). Definir qual o alcance de uma infraestrutura, para quem ela é funcional e para quem representa um problema, e o que ela representa em termos de aspirações, ideais e imaginários, são questões que necessitam de uma resposta empírica acompanhada de uma reflexão metodológica importante ${ }^{8}$.

\footnotetext{
7 Susan Leigh Star (1954-2010), mesmo tendo a TAR como uma de suas inspirações, nunca renunciou categorias antropológicas em suas pesquisas. A ideia de que os atores possuem perspectivas, pontos de vista e formas de produção de significado importantes para a pesquisa de infraestruturas, as quais podem ser captadas através da etnografia, perpassa toda sua obra em um interessante diálogo com as categorias analíticas e métodos da TAR. Para uma compilação de seus trabalhos ver Bowker et al (2015).

${ }^{8}$ Star (1999), recorre à etnografia para estudar as infraestruturas e desenvolve uma interessante discussão metodológica a respeito do que significa a etnografia das infraestruturas. Outros estudos etnográficos das infraestruturas podem ser encontrados em: Jensen; Winthereik, (2013); Harvey; Knox, (2015; Harvey et al (2017); Hetherington (2019).
} 
A partir de seus estudos etnográficos, Star (1999) e Bowker; Star (1999) trouxeram para o primeiro plano as práticas que estavam nos bastidores das infraestruturas. Eles identificaram certas propriedades comuns desses arranjos sociotécnicos que ainda não haviam sido postas de maneira clara. Algumas dessas dimensões podem ser conferidas no quadro 1:

\begin{tabular}{|c|c|}
\hline \multicolumn{2}{|c|}{$\begin{array}{c}\text { Quadro } 1 \text { - Propriedades das infraestruturas sob ponto de vista sociotécnico e } \\
\text { organizacional }\end{array}$} \\
\hline Incorporação (Embeddedness) & $\begin{array}{l}\text { A infraestrutura está inserida dentro de outras } \\
\text { estruturas, arranjos sociais e tecnologias. Os } \\
\text { vários aspectos coordenados das infraestruturas } \\
\text { são de difícil distinção. Nós, frequentemente, } \\
\text { estamos nas infraestruturas sem se dar conta dos } \\
\text { aspectos coordenados que elas mantêm com } \\
\text { outros sistemas técnicos. }\end{array}$ \\
\hline Transparência & $\begin{array}{l}\text { As infraestruturas são construídas para se } \\
\text { tornarem "transparentes", isto é, elas devem } \\
\text { suportar nossas práticas sem que nos demos } \\
\text { conta de que estão operando. Quando ligamos } \\
\text { o computador não pensamos no sistema } \\
\text { elétrico ou na rede de internet que o suporta. } \\
\text { Simplesmente nos ocupamos de nossas tarefas } \\
\text { a serem feitas. }\end{array}$ \\
\hline Se tornam visíveis quando colapsam & $\begin{array}{l}\text { A qualidade de transparência das infraestruturas } \\
\text { se perde quando elas falham em nos atender. } \\
\text { Nós não nos atentamos para a coordenação da } \\
\text { rede de abastecimento de água até sofrermos } \\
\text { com uma crise hídrica. }\end{array}$ \\
\hline $\begin{array}{l}\text { Alcance ou escopo (espacial ou } \\
\text { temporal) }\end{array}$ & $\begin{array}{l}\text { A infraestrutura tem alcance além de um único } \\
\text { evento, local ou prática. }\end{array}$ \\
\hline $\begin{array}{l}\text { Aprende-se sobre infraestruturas } \\
\text { fazendo parte de uma "comunidade de } \\
\text { práticas" }\end{array}$ & $\begin{array}{l}\text { Pode-se conhecer mais a fundo a infraestrutura } \\
\text { se participarmos de grupos que as } \\
\text { desenvolvem, consertam e as atualizam. } \\
\text { Aprender sobre os usos de dados e criptografias } \\
\text { da internet é um bom exemplo. Fazendo parte } \\
\text { de grupos de desenvolvedores de códigos, } \\
\text { podemos nos especializar e nos familiarizar } \\
\text { com a infraestrutura da internet. Aprender } \\
\text { sobre infraestruturas, portanto, é uma atividade } \\
\text { coletiva. É participando da comunidade de } \\
\text { práticas de uma determinada infraestrutura que } \\
\text { passamos a entender suas convenções, padrões } \\
\text { e linguagens específicas, bem como suas rotinas } \\
\text { e formas de vida. }\end{array}$ \\
\hline Incorporação de padrões & $\begin{array}{l}\text { As infraestruturas operam e se conectam com } \\
\text { outras infraestruturas através de padrões e }\end{array}$ \\
\hline
\end{tabular}




\begin{tabular}{|l|l|}
\hline & $\begin{array}{l}\text { classificações que precisam ser incorporadas e } \\
\text { compartilhadas. Por exemplo, a padronização } \\
\text { da voltagem de uma rede de energia é um } \\
\text { padrão compartilhado entre as infraestruturas } \\
\text { de uma determinada região. A incorporação de } \\
\text { tais padrões não é algo automático ou natural, } \\
\text { requer processos sociais que devem ser } \\
\text { compreendidos. }\end{array}$ \\
\hline Construídas sobre uma base instalada & $\begin{array}{l}\text { Infraestruturas não nascem na ausência de } \\
\text { velhas infraestruturas. Elas crescem com base } \\
\text { em velhas instalações e formatos pré-existentes. }\end{array}$ \\
Quando um sistema novo é desenhado, ele \\
Modificam-se de maneira incremental \\
necessita se compatibilizar com sistemas \\
antigos, mesmo que isso seja provisório. \\
$\begin{array}{l}\text { Por conta de serem grandes, possuírem } \\
\text { diferentes camadas, serem complexas e } \\
\text { adquirirem significados diferentes dependendo } \\
\text { da localidade em que estão instaladas, as } \\
\text { infraestruturas demoram para serem } \\
\text { modificadas. Isso leva tempo e negociação. } \\
\text { Portanto, as infraestruturas são modificadas de } \\
\text { maneira incremental, nunca sendo } \\
\text { transformadas totalmente de uma só vez. }\end{array}$ \\
\hline
\end{tabular}

Fonte: elaborado pelo autor com base em STAR (1999) e BOWKER; STAR (1999).

Essas primeiras características das infraestruturas, que foram obtidas através de trabalhos empíricos desses autores, serviram de base para novos estudos sobre uma diversidade de temas relacionados às infraestruturas, alguns dos quais trataremos a seguir.

\section{Infraestruturas do conhecimento científico}

Um tema de estudo das infraestruturas que recebeu grande atenção se refere ao papel das infraestruturas na produção do conhecimento científico. A ciência moderna depende fundamentalmente de sofisticadas infraestruturas para testar hipóteses, fazer observações, realizar experimentos, gerar e compartilhar dados e manter um sistema global de produção.

Os ESCT demonstraram que a produção de novos conhecimentos, longe de ser o resultado de epifanias, refere-se a um constante processo de representação, interação e comunicação coletiva (LYNCH; WOOLGAR, 1990; PICKERING, 1992; KNORRCETINA, 1999). Permite-se com isso "mobilizar a natureza" para dentro das 
infraestruturas laboratoriais e submetê-la a sucessivas transformações (LATOUR; WOOLGAR, 1997). Essa feitura dos fatos científicos na atualidade é fundamentalmente uma atividade infraestruturada e globalmente conectada.

A respeito da maneira que as infraestruturas modificam as metodologias e as práticas científicas, é surpreendente como o avanço das infraestruturas informacionais e computacionais impactou a ciência em diversas áreas nas últimas décadas (HEY et al. 2009). As chamadas e-sciences ou cyberinfraestruturas da ciência trouxeram questões a respeito do que são os experimentos científicos na atualidade e o que pode ser considerado uma evidência ao se gerar e testar hipóteses com base em simulações (LENHARD et al, 2006; HINE, 2006; WOOLGAR; COOPMANS, 2006). As cyberinfraestruturas da ciência reconfiguraram a prática científica, passando a exercer um papel determinante na produção de dados, novos resultados e na maneira que a ciência se organiza enquanto sistema de trabalho (WOOLGAR, 2014).

O caso das ciências climáticas é um exemplo interessante dessas transformações. A partir da II Guerra Mundial, a meteorologia obteve grandes avanços tecnocientíficos nos Estados Unidos e Europa. Tais avanços se referem, por um lado, à construção de amplas redes de observação da atmosfera e de telecomunicação para o compartilhamento de dados meteorológicos e, por outro, à constituição de instituições internacionais como a OMM (Organização Meteorológica Mundial) e suas sub-redes regionais, nacionais e locais (MIGUEL, 2017). De acordo com Edwards (2006), o estabelecimento e a consolidação dessas amplas redes administradas pela OMM representam articulações sociotécnicas que resultam em uma "infraestrutura global do conhecimento meteorológico". Edwards (2010) considera que a atmosfera global é produto dessa "ampla máquina" formada por dispositivos técnicos, padrões, regulamentos, modelos computacionais, supercomputadores, sistemas de compartilhamento de dados e acordos firmados internacionalmente. Em outras palavras, para que se tenha um objeto de estudo como o clima global, foi preciso construir uma infraestrutura do conhecimento global sem a qual a ideia de clima global não se sustentaria empiricamente.

Os experimentos com o clima global acontecem principalmente através de modelos computacionais, chamados “modelos climáticos". Um aspecto interessante desses modelos e seus experimentos é que, para testar, por exemplo, a hipótese do aquecimento global, os dados ditos "observacionais", que poderiam ser chamados de "dados brutos", não existiam 
na prática. Todos os dados passaram (e passam) pelos modelos climáticos e, com isso, puderam ser agrupados e tratados de maneira que um passado climatológico global pudesse ser construído através de simulações. Com base nesse passado climatológico, foram realizadas projeções climáticas com a elevação dos níveis de carbono na atmosfera e sem essa elevação. Os resultados permitiram constatar que o aumento das emissões antrópicas é responsável pelo maior aquecimento atmosférico. Esses experimentos em escala planetária não seriam possíveis se a climatologia não dispusesse de "uma ampla máquina" (EDWARDS, 2010), isto é, de uma infraestrutura amplamente conectada para realizar tais experimentos.

Esse exemplo nos ajuda a entender o quão dependem a ciência de suas infraestruturas. Isso faz com que as infraestruturas científicas se tornem um importante objeto de estudo social na atualidade por diferentes motivos. Algumas questões importantes que têm sido estudadas são: quais os novos modos de organização da ciência na era atual das cyberinfraestruturas? De que maneira as simulações e uso de grandes bancos de dados impactaram as metodologias científicas? (HEY et al 2009). Como a objetividade e a empiria adquiriram novos significados com as transformações ocorridas nas infraestruturas laboratoriais? (DASTON, 2014). Como essas transformações ocasionadas pela introdução de novas infraestruturas no sistema global impacta a ciência e a política científica nos países menos desenvolvidos? (NEVES, 2014; MIGUEL, 2017, MIGUEL et al 2019), dentre outras questões.

\section{Infraestruturas da informação e comunicação}

As infraestruturas exercem um papel central na maneira que as informações circulam pela sociedade e na maneira que nos comunicamos. Atualmente, a internet pode ser considerada "uma infraestrutura das infraestruturas", dada a dependência que os outros sistemas e as pessoas têm dessa rede global. Um volumoso número de estudos sociais tem discutido o papel das tecnologias da informação e comunicação (TIC's) nas mais diferentes esferas da vida social. Sem que se possa tratar de todos esses temas aqui, cito apenas alguns que são de grande relevância:

a) implicações entre o crescimento das redes digitais e o estabelecimento de um mercado de coleta e venda de dados pessoais nos ambientes digitais (SILVEIRA, 2017); 
b) o impacto das TIC's nas formas de se fazer política (CASTELLS, 2014; CARTY, 2015);

c) a cibercultura e as novas formas de se comunicar e interagir por meio das redes (LEVY, 2010);

d) o papel do hackativismo como forma de resistência (JORDAN; TAYLOR, 2004; ASSANGE, 2013);

e) o significado do virtual e suas implicações na noção de realidade e consciência (TURKLE, 2005; WOOLGAR, 2012);

f) as novas formas de organização do trabalho na era digital e a luta de classes (ANTUNES, 2020);

g) as políticas discriminatórias dos algoritmos (O’NEIL, 2016);

h) a questão da pós-verdade na era da informação (KALPOKAS, 2018; CESARINO, 2019);

i) o movimento software livre e a questão da propriedade na era digital (EVANGELISTA, 2010);

j) o que são infraestruturas da informação e como se organizam enquanto sistema sociotécnico (BOWKER et al, 2010; JACKSON, et al 2007).

Estes são apenas alguns dos temas que demonstra a grande importância do estudo das infraestruturas da informação, comunicação e sociedade na atualidade. A tendência é pensar essas infraestruturas como sistemas interconectados e politicamente disputados que estão articulados com a sociedade e com os indivíduos de maneira complexa.

\section{Infraestruturas e tecnopolíticas}

Infraestruturas são formas eficientes de materializar categorias de poder, expressar visões políticas e exercer formas de governo. A célebre obra de Michel Foucault, "Vigiar e Punir" (1999), fala da figura arquitetural chamada "panóptico" (figura 1). Idealizada pelo filósofo utilitarista Jeremy Bentham (1748-1832), o panóptico fora concebido como uma infraestrutura prisional na qual um único vigilante seria capaz de observar todos os prisioneiros, sem que estes pudessem saber se estavam ou não sendo observados. Foucault (1999) analisa que a arquitetura panóptica representa um dispositivo que desindividualiza o poder numa "certa distribuição concertada dos corpos, das superfícies, das luzes, dos 
olhares; numa aparelhagem cujos mecanismos internos produzem a relação na qual se encontram presos os indivíduos” (p.167). Como uma forma arquitetônica na qual está encarnada uma concepção específica de organização dos corpos, o panóptico é um exemplo de infraestrutura concebida para exercer uma forma de "tecnopolítica" disciplinar.

Figura 1 - Panóptico de Jeremy Bentham.
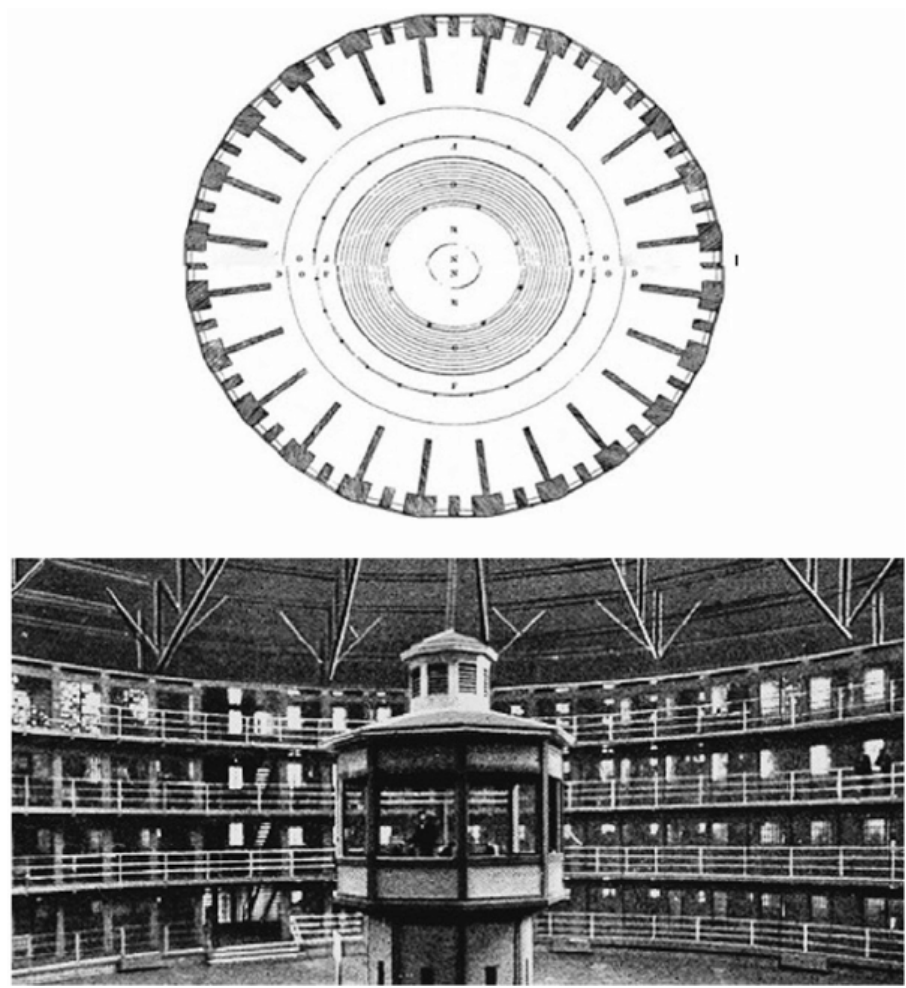

Imagem: Google imagens, 2020.

Assumir a dimensão tecnopolítica das infraestruturas é assumir a noção de que os objetos técnicos possuem qualidades políticas, rompendo assim a noção de neutralidade da ciência e da tecnologia (DAGNINO, 2008). Em seu influente artigo, "artefatos têm política?", Langdon Winner (1986) argumenta que:

[...] as estruturas e os sistemas da cultura material moderna podem ser apreciados com precisão não apenas por suas contribuições em termos de eficiência e produtividade, bem como seus efeitos ambientais secundários negativos ou positivos, mas também pelas maneiras nas quais eles podem incorporar formas específicas de poder e autoridade (WINNER, 1986, p.01).

Um exemplo trazido por Winner (1986) dessa incorporação da política nas infraestruturas fala dos viadutos de Long Island (figura 2), no estado de Nova York. Winner relata que o empreiteiro de estradas, parques, pontes e outras obras públicas de Nova 
Iorque, Robert Moses, entre as décadas de 1920 e 1970, construiu viadutos de acordo com especificações que deveriam desencorajar a presença de ônibus nas avenidas de parques. Os motivos para isso refletem os preconceitos de classe social e racial de Moses. Proprietários de automóveis, brancos, de "classe alta" ou "classe média burguesa", estariam livres para usar as avenidas do parque para recreação e deslocamento. Pessoas pobres e negros, que normalmente usavam transporte público, eram mantidas afastadas dessas estradas porque os ônibus com mais de 3 metros de altura não podiam passar pelos viadutos. Uma das consequências foi limitar o acesso de minorias raciais e de baixa renda ao Jones Beach, o mais aclamado parque público de Moses.

Figura 2 - Viaduto que dava acesso ao Jones Beach Park, Long Island, NY, 1926.

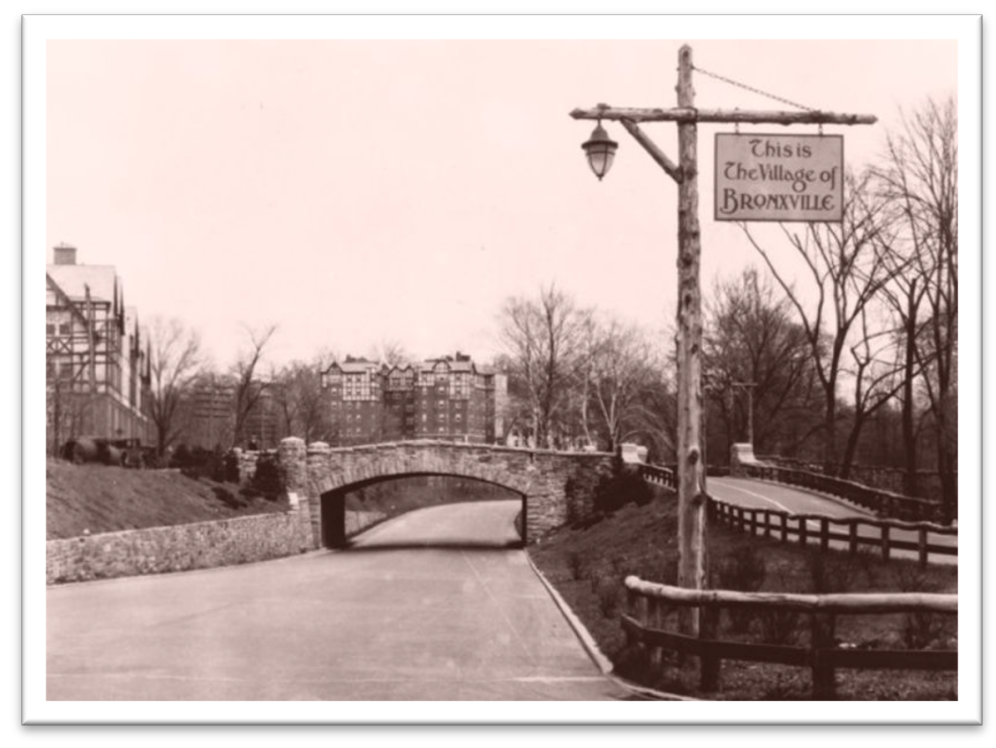

Fonte: CAMPANELLA, 2017.

Schnitzler (2018) destacou que, de várias maneiras, o Apartheid para existir como projeto político, dependeu de modalidades de poder infraestruturadas. Nas áreas urbanas da África do Sul, os residentes negros eram considerados moradores temporários cuja residência permanente era imaginada nas áreas rurais delimitadas nos chamados "Bantustões" ". As infraestruturas nas áreas urbanas se tornaram símbolos, condutores e

9 A partir de 1910, quando a África do Sul se tornou independente da Coroa britânica, várias leis segregacionistas foram implementadas. Entre elas, o Native Labour Act, de 1913, estendeu aos trabalhadores urbanos o sistema de submissão vigente nas fazendas, dividindo a África do Sul em duas partes: 7\% do território nacional foram deixados aos negros, os quais representavam $75 \%$ da população, e $93 \%$ das melhores terras foram entregues aos brancos, que correspondiam a 10\% da população. Em 1923, o Native Urban Act limitou drasticamente a possibilidade dos negros se instalarem em cidades consideradas redutos dos brancos. (PEREIRA, 2018, p.140). 
formas de poder no Apartheid. A segregação no transporte urbano, as placas em locais públicos que limitavam a entrada de negros, "whites only", são exemplos claros de como as infraestruturas servem para que categorias de poder sejam constituídas de maneira material e simbólica (figura 3).

Figura 3 - Placa utilizada no regime do Apartheid diz: "Para uso de pessoas brancas. Estes locais públicos e as respectivas amenidades foram reservados para uso exclusivo de pessoas brancas". As infraestruturas materializavam no contexto segregacionista do Apartheid uma forma de organização e distribuição dos corpos no espaço que configurava as identidades raciais, suas possibilidades de mobilidade, seus hábitos e suas rotinas.

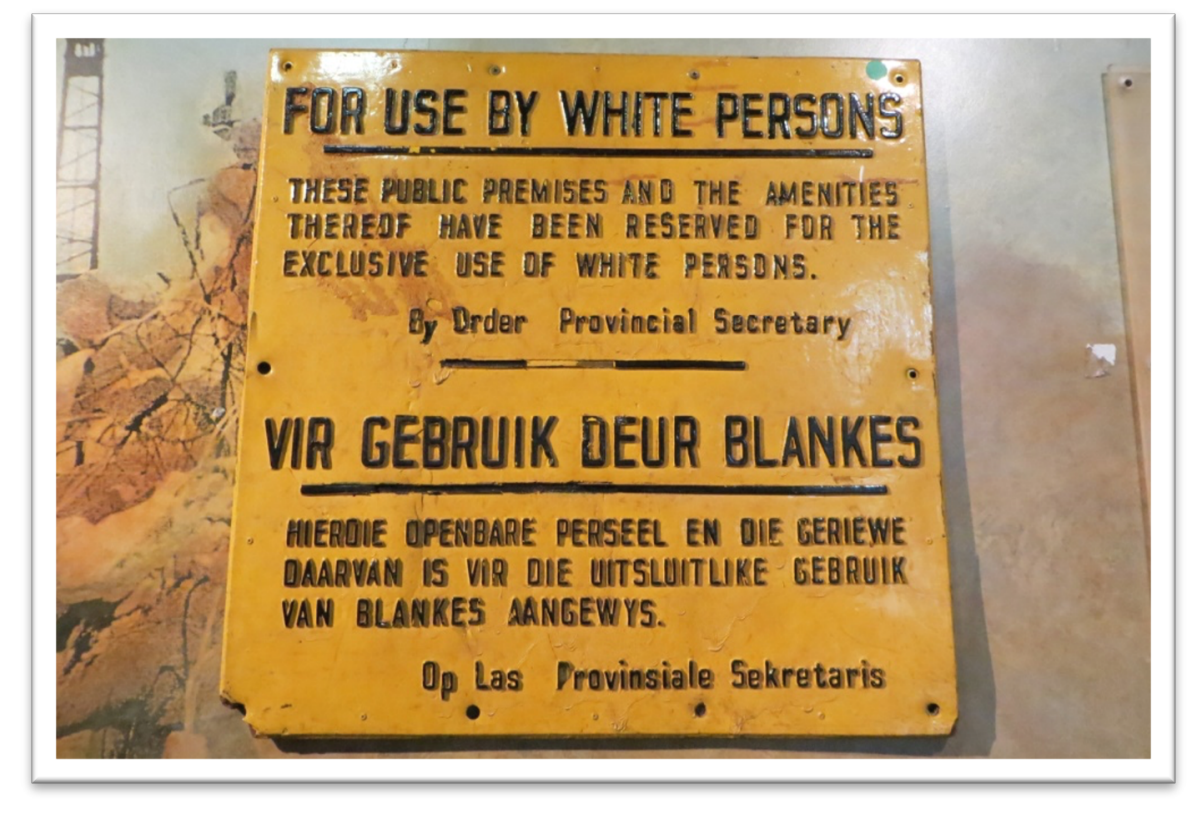

Foto: Google Images, 2020.

Percebe-se, portanto, que refletir a respeito de como são desenhadas e planejadas as infraestruturas e o que elas produzem em termos de efeitos políticos é fundamental para que se possa expor quais formas de autoridade estão ganhando corpo com esses sistemas; quem será excluído dos ganhos e das funcionalidades propostas com essas infraestruturas; quem perderá ou ganhará mais direitos com a existência desses sistemas; dentre tantas outras questões.

Outro exemplo do caráter coprodutivo das infraestruturas e formas de poder e de autoridade pode ser reconhecido nas políticas ambientais que visam a sustentabilidade. Ao pensar nas implicações políticas dos planos de expansão das usinas nucleares como principal fonte de geração de energia, Denis Haynes (1977) argumentou que apenas governos autoritários poderiam aceitar esses planos, pois a geração de energia nuclear, segundo ele, exige a presença de um poder controlador central e tecnocrático devido aos protocolos de segurança e aos grandes riscos assumidos pelo governo. Ao contrário, a 
energia solar, segundo o autor, estaria mais a fim das formas mais democráticas de organização social, pois permite a geração distribuída de energia limpa dando maior autonomia e poder de decisão aos usuários. Haynes (1977) argumenta, portanto, que nossas escolhas tecnológicas também são escolhas do modo como queremos viver em sociedade; são escolhas a respeito de como queremos tomar as decisões públicas e de qual autoridade delegamos aos conselhos de especialistas e ao governo.

Nesses mesmos termos, se refletirmos a respeito de que tipo de política ambiental está em curso com a predominância das usinas termoelétricas (maiores emissoras de carbono) nos países industrializados, podemos concluir que, no atual contexto das mudanças climáticas, essa forma de gerar energia é produtora de injustiça social, na medida em que o agravamento das mudanças climáticas pela emissão de carbono impacta diretamente a vida dos mais pobres, gerando imigrações em massa, fome e crise hídrica. As termoelétricas são, portanto, fonte de "injustiça climática", pois suportam a produção de riqueza nos países centrais do capitalismo industrial e perpetuam as desigualdades nos países menos desenvolvidos.

Outro aspecto relacionado às nossas escolhas tecnológicas e de infraestrutura, diz respeito à relação entre produção de conhecimento e ação no contexto das mudanças climáticas. Miguel (2017) discute como a política e a ciência das mudanças climáticas, ao eleger os cenários e simulações produzidas por modelos computacionais como o ferramental central para orientar os planos de adaptação às mudanças climáticas, pode resultar em propostas de ação confiadas aos dispositivos de segurança controlados pelo Estado. Segundo o autor, os modelos climáticos e seus cenários de impacto produzem racionalidades governamentais de caráter biopolítico que servem à administração centralizada do Estado. Essas "pragmáticas de governo", constituídas como forma de leitura predominante das mudanças climáticas, frequentemente excluem outros saberes da lista de opções para pensar a adaptação. Tais "tecnopolíticas das mudanças climáticas" reduzem a complexidade das questões que envolvem as mudanças climáticas a uma linguagem dirigida a processos de gestão tecnocráticos que minimizam a participação pública. Sendo assim, as escolhas tecnológicas que fazemos para compreender as mudanças climáticas, são também a forma como pretendemos agir no mundo aquecido.

Estes e outros exemplo nos fazem ver que as infraestruturas podem ser formas efetivas de exercer a política por outros meios. Os estudos sociais, portanto, têm um papel 
fundamental de deslindar tais formas incorporadas de poder e estimular a discussão pública a respeito do que produzem tais infraestruturas.

\section{As promessas das infraestruturas}

Um dos ganhos dos estudos sociais ao adentrarem o tema das infraestruturas foi chamar a atenção para os imaginários e aspirações que se constituem com as infraestruturas. Os discursos institucionais daqueles que desenham, financiam e gerenciam infraestruturas aparecem frequentemente como "promessas" (ANAND, et al. 2018) em termos de modernizar, tornar eficiente, reduzir custos, proporcionar bem-estar a toda população. Tais promessas de progresso e desenvolvimento econômico nascem aliadas aos projetos de infraestruturas.

Defensores das ideias neoliberais, por exemplo, argumentam que tipos particulares de infraestruturas são necessários ao bom funcionamento do capitalismo. Por exemplo, as estradas, aeroportos, sistemas de energia, telecomunicações, dentre outras infraestruturas que servem para garantir a circulação de capital e trabalho. Estas infraestruturas precisam ser continuamente aprimoradas, preferencialmente, com financiamento público. Contudo, no contexto de países subdesenvolvidos, percebe-se que tais infraestruturas atendem a interesses privados e às elites econômicas. A política neoliberal faz com que infraestruturas sejam formas de expressão dos interesses de classe, tornando-se assim, formas de agravamento das desigualdades sociais.

A construção das infraestruturas públicas de grande porte envolve negociações entre poder público e privado, que resultam em contratos bilionários entre o Estado e corporações globais. Politicamente, representam uma transferência de responsabilidades do poder público para o setor privado que, sob a ótica neoliberal, deve se encarregar da gestão das infraestruturas e companhias públicas. Se atentarmos para a realidade do Brasil, percebemos que as políticas de privatização tiveram e têm como alvo infraestruturas consideradas estratégicas, por exemplo, o setor de energia, telecomunicações, mineração, sistema bancário, aeroportos, rodovias etc. Contudo, a promessa neoliberal de desenvolvimento e bem-estar social através da privatização de infraestruturas não se realizou no caso brasileiro. O que verificamos são escândalos que envolvem 
irresponsabilidades socioambientais, negligência com os serviços prestados à população e corrupção ${ }^{10}$.

A preponderância da ótica neoliberal distorce a imagem construída pelo Estado moderno como provedor e gestor das infraestruturas estratégicas, que fariam parte da política de desenvolvimento. Na ótica Keynesiana, as infraestruturas ocupam um papel central como política econômica e como forma de constituição do poder do Estado, compreendido como o definidor dos rumos da modernização. Em uma lógica de estatização das infraestruturas, o Estado deveria aumentar seu poder conforme incentiva o desenvolvimento de infraestruturas modernas sob seu controle. As infraestruturas, nesse sentido, adquirem um papel geopolítico importante, sendo frequentemente associadas aos ideais de soberania do Estado Nação (figura 4).

Figura 4 - Presidente Lula ergue uma bandeira do Brasil nas instalações da Petrobras. Ao fundo, pode-se ler a faixa na plataforma com a frase "orgulho do povo brasileiro". Ilustra-se, portanto, como as infraestruturas podem representar soberania, produzir uma nação imaginada, e criar a imagem de um Estado forte que atende aos interesses de sua população.

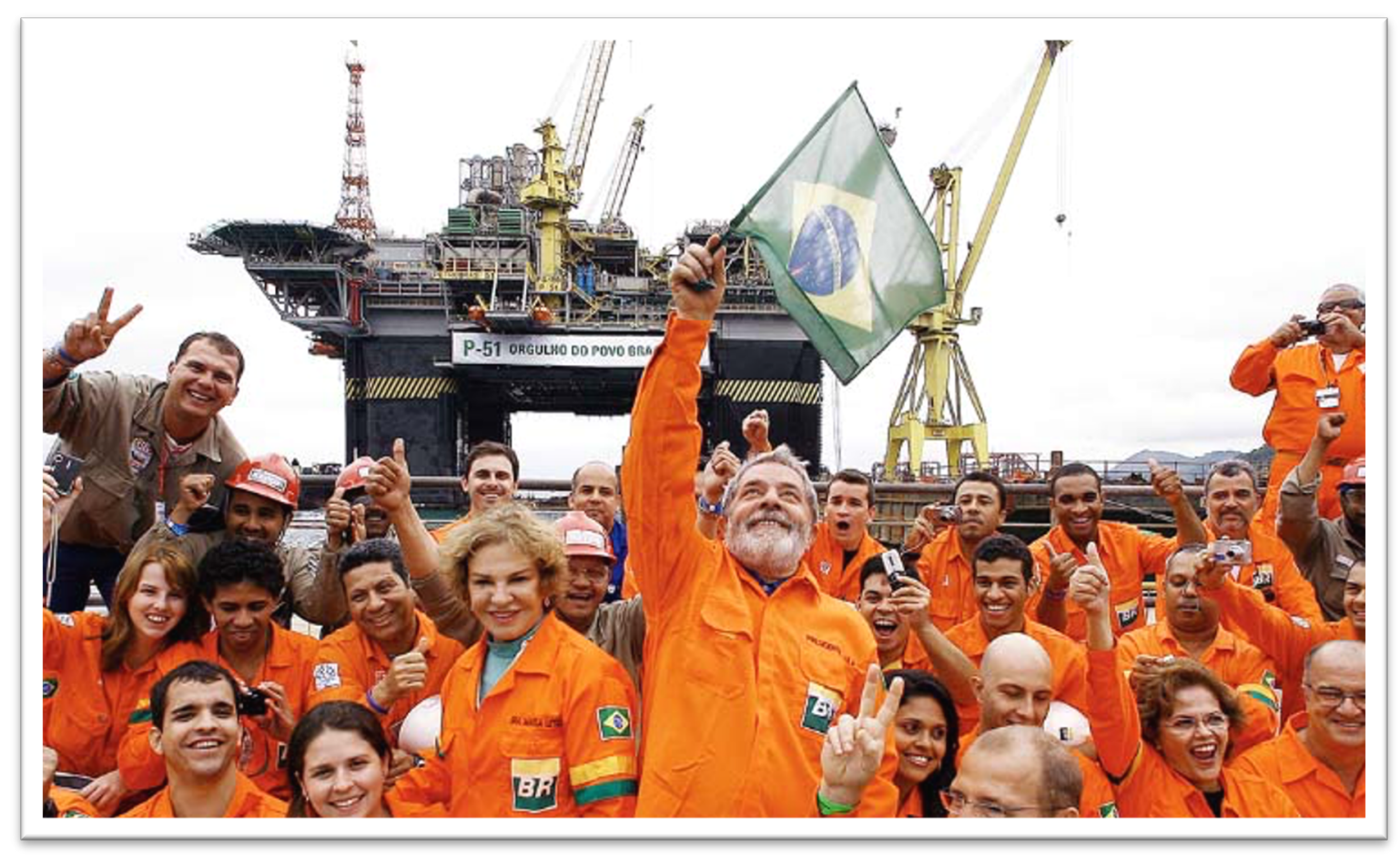

Foto: Google Imagens, 2020.

10 Para ficar em alguns casos, lembremos do rompimento da represa de Brumadinho sob gestão da Vale; da construção da usina de Belo Monte; dos apagões do setor elétrico na década de 1990; dos serviços prestados pelas empresas de telecomunicação que são de má qualidade e possuem um alto custo; das negociações realizadas através da Petrobrás sobre a compra de refinarias...etc. Todos esses casos envolvem processos de privatização que resultaram em grandes desilusões a respeito do que havia sido prometido ao povo brasileiro como recompensa pela venda dessas infraestruturas que eram parte do patrimônio público. 
Com a predominância da política neoliberal, questões infraestruturais e de soberania representam desvios dos investimentos públicos que poderiam ser, segundo a ótica capitalista, aplicados de maneira mais coerente com a política definida pelas grandes corporações. Com isso, as infraestruturas se convertem em lócus onde se perpetuam as desigualdades. Por exemplo, o acesso aos sistemas de saúde e educação privados são um privilégio daqueles que têm dinheiro. A maioria dos aparelhos urbanos atende primeiro as regiões mais ricas das cidades e raramente chegam às periferias.

Um caso ilustrativo é o do apagão elétrico no Amapá em 2020. Após um incêndio na subestação do estado, ocorreu uma crise energética que afetou quase 90\% do estado, deixando boa parte da população sem luz por semanas ${ }^{11}$. Sem energia, a população do Amapá passou a sofrer com falta de água potável; com a incapacidade de manter alimentos refrigerados; com a escassez de produtos nos mercados; com a impossibilidade de sacar dinheiro nos caixas eletrônicos; com o isolamento produzido pela incapacidade de recarregar aparelhos eletrônicos como celulares; dentre outros problemas resultantes da falha do sistema elétrico. A subestação de Macapá pertence a uma sociedade empresarial chamada de "Linhas de Macapá Transmissora de Energia (LMTE)", controlada pelo capital financeiro internacional. Desde 2008, a empresa recebia, anualmente, uma receita de $\mathrm{R} \$ 135$ milhões para oferecer serviços de linhas de transmissão e subestações. Porém, na busca de diminuir custos, a empresa colocou equipamentos de baixa qualidade que se degradaram e não foram substituídos ${ }^{12}$. O apagão elétrico revelou que, enquanto a população sofria as consequências do apagão, o Amapá produzia e exportava energia de quatro hidrelétricas aos estados mais ricos em outras regiões do Brasil. Evidenciou-se com isso que o discurso que afirma que a construção de hidrelétricas traz desenvolvimento à região das usinas é uma cilada (vide também o caso de Belo Monte). Sem energia, a população fez protestos que

11 Fonte: https://brasil.elpais.com/brasil/2020-11-14/capital-do-amapa-vive-dias-medievais-a-luz-develas-e-com-agua-de-poco-colhida-com-

balde.html?utm_medium $=$ Social\&utm_source $=$ Twitter\&ssm=TW_BR_CM\#Echobox $=1605318401$ acesso 19/01/2021;

12 Fonte: https://midianinja.org/news/um-mes-apos-apagao-no-amapa-mais-de-50-entidades-assinamcarta-contra-privatizacao-do-setor-eletrico/ acesso 19/01/2020. 
foram duramente repreendidos pela polícia ${ }^{13}$. Quando a energia voltou em sistema de rodízio, atendeu primeiro aos bairros nobres e a periferia permaneceu na escuridão ${ }^{14}$.

Notamos, portanto, que infraestruturas estão profundamente relacionadas às dinâmicas e tensões entre o Estado, o setor privado e a sociedade civil. Elas se constituem em meio a narrativas de modernização, progresso e bem-estar da população. Não obstante, quando essas promessas se quebram junto com as infraestruturas, agravam-se as profundas desigualdades sociais.

\section{Infraestruturas e a vida no Antropoceno}

A crise ambiental em escala global, cuja expressão mais clara são as mudanças climáticas e sua ampla cadeia de efeitos nos mais diversos ecossistemas, fez com que toda uma série de questionamentos ocorresse nas ciências naturais e sociais. O termo “antropoceno" tem sido utilizado para designar a época em que vivemos, na qual o impacto das ações humanas adquiriu escalas geológicas, transformando o meio ambiente em escala planetária (CRUTZEN; STOERMER, 2000). O primeiro problema conceitual que o antropoceno causa nas ciências sociais é uma perturbação em várias divisões de categoria, por exemplo, entre natureza e cultura, humanos e não-humanos, global e local, história humana e história da Terra (CHAKRABARTY, 2009; LATOUR, 2020). O conceito de antropoceno causa uma inversão da relação entre figura e fundo. A Terra, antes palco das nossas ações, torna-se agente que responde aos nossos atos. Isso requer que a concepção antropocêntrica da ação seja repensada. O foco da análise passa a ser direcionado para os múltiplos tipos de agenciamentos, alianças e enredamentos e novas formas de saber e de fazer política, que se formam nessa nova época para que possamos aprender a "viver no tempo das catástrofes” (HARAWAY, 2016; STENGERS, 2015; TSING, 2015).

Os termos "ambiente" e "infraestrutura" compartilham um território conceitual que foi perturbado com o advento do antropoceno. Ambos os termos se referiam a um

13 Fonte: https://brasil.elpais.com/brasil/2020-11-14/capital-do-amapa-vive-dias-medievais-a-luz-develas-e-com-agua-de-poco-colhida-com-

balde.html?utm_medium=Social\&utm_source=Twitter\&ssm=TW_BR_CM\#Echobox $=1605318401$ acesso 19/01/2020.

14 Fonte: https://brasil.estadao.com.br/noticias/geral,amapa-rodizio-de-energia-atende-bairros-nobres-eperiferia-fica-no-escuro, 70003506808 acesso 19/01/2020. 
determinado "contexto" da ação humana, espacialmente delimitado e de fácil reconhecimento, os quais passam agora por redefinições importantes. O "ambiente" ou "meio ambiente", em uma distinção clássica, precederia a infraestrutura, da mesma forma que a paisagem precederia a arquitetura de uma ponte. Sendo assim, "O ambiente seria a infraestrutura da infraestrutura" (HETHERINGTON, 2019, p.06). Mas essa distinção já não funciona na medida em que são as infraestruturas capitalistas globais (da indústria, do transporte, da produção de energia, alimento etc.) que têm interferido diretamente no ambiente, mas também têm recebido a resposta desse "ambiente" na forma de catástrofes que arrasam as infraestruturas e as populações que delas dependem. Nem as infraestruturas nem o ambiente, portanto, são o background que suportam um ao outro, mas estão dinamicamente relacionados em um movimento de retroalimentação que traz desafios à nossa compreensão.

Uma das questões do antropoceno diz respeito a como as infraestruturas, cada vez mais entrelaçadas umas nas outras em escala planetária, resistirão às catástrofes que estão por vir. O termo "crise", que se refere a tantas dimensões na atualidade, refere-se também a uma crise das infraestruturas, que ocorre em escalas nunca presenciadas devido ao alto grau de interdependência desses sistemas. Precisa-se, portanto, que se dirija um outro olhar aos processos que constituem a integração desses sistemas técnicos entre si e com aquilo que costumávamos chamar de "ambiente". Tal olhar precisa alcançar os efeitos que as catástrofes produzirão em termos de “desentrelaçar" essas infraestruturas, produzindo uma cadeia de eventos catastróficos cuja resposta se tornará cada vez mais difícil de ser planejada $^{15}$ (MIGUEL; TADDEI; FIGUEIREDO, no prelo).

Nota-se que o antropoceno torna as infraestruturas um lócus de análise central para pensar as crises dentro das crises que vivemos na atualidade. Jensen e Morita (2015), ao sugerirem que as infraestruturas podem ser pensadas como "experimentações ontológicas", isto é, "locais onde vários agentes se encontram, se envolvem e produzem novos mundos" (p.85), nos indicam um caminho possível para rastrear transformações, delinear os contornos das ontologias emergentes e, com isso, também perceber um ponto de partida para considerar as questões centrais de uma política não humanista: "com que outras criaturas vivemos? E como podemos viver de forma diferente?”. O antropoceno exige que

15 Pensemos no impacto sistêmico da pandemia de Covid 19 e seus inúmeros efeitos nas mais diferentes infraestruturas (MIGUEL; TADDEI; FIGUEIREDO, no prelo). 
inventemos novas formas de perceber nossa relação com o mundo e novos modos de fazer política. As infraestruturas são, portanto, sítios importantes do trabalho antropológico e do esforço mais amplo de compreender o advento do antropoceno.

\section{Considerações finais}

Nesse texto, busquei esclarecer como o ponto de vista analítico das infraestruturas pode ser produtivo e recomendável para pensar diferentes questões que estão colocadas como desafios na contemporaneidade. Se viver na modernidade pode ser compreendido como "viver por meio de infraestruturas", precisamos aprender a lidar conceitualmente e empiricamente com esses objetos que se apresentam cheios de sutilezas materiais e imateriais, nos desafiando a pensar para além das categorias tradicionais da sociologia. Os ESCT produziram volumosos estudos que indicam como problemas que envolvem conhecimento, tecnologia e sociedade não podem ser reduzidos aos fatores ditos sociais, tão pouco serem explicados pelo determinismo científico-tecnológico. Estes problemas exigem formas mais reflexivas de compreensão, que permitam enxergar a tecnologia e o conhecimento como parte constitutiva da sociedade. As infraestruturas são um exemplo claro do nexo entre sociedade, tecnologia, natureza e cultura. Também demonstram a profunda associação entre formas de poder e aparatos técnicos. O ponto de vista analítico das infraestruturas pode contribuir, portanto, para pensarmos novos conceitos, ações transdisciplinares e, com isso, permitir experimentações entre diferentes formas de saber e de fazer política.

\section{Referências}

ALTHUSSER, L. Ideologia $e$ aparelhos ideológicos do Estado. Martins Fontes, $1^{\mathrm{a}}$ Ed. 1970.

ANAND, N.; GUPTA, A.; APPEL, H (eds.). The Promisse of infrastructure. Duke University Press. 2018.

ANTUNES, R. (org.). Uberização, trabalho digital e indústria 4.0. Boitempo, 2020.
ASSANGE, J. Cyberpunks. Liberdade e o futuro da internet. Biotempo, 2013.

BIJKER, W.E.; HUGHES, T. P.; PINCH, T.J.; (eds.) The Social Construction of Technological Systems: New Directions on Sociology and History of Technology, 1st.ed. Massachusetts The MIT Press, 1987.

BOWKER, G. C. (1995) "Second Nature Once Removed: Time, Space and 
Representations," 'Time and Society 4(1): 47-66.

BOWKER, G.; STAR, S. L. Sorting Things Out: Classification and Its Consequences. Cambridge, MA, and London: MIT Press, 1999.

BOWKER, G. C.; TIMMERMANS, S.; CLARKE, E. A.; BALKA, E. Boundary Objects and Beyond. Working with Leigh Star, MIT Press. 2015.

BOWKER, G. C.; BAKER, K.; MILLERAND, F.; RIBES, D. Toward Information Infrastructure Studies: Ways of Knowing in a Networked Environment. International Handbook of Internet Research, p.97-117, 2010.

CAMPANELLA, T.; J. Robert Moses and His Racist Parkway, Explained. Bloonsberg Citylab, $2017 . \quad$ In: https://www.bloomberg.com/news/arti cles/2017-07-09/robert-moses-and-his-

racist-parkway-explained Acesso: 23/01/2021.

CARTY, V. Social Movements and New Technology. Taylor \& Francis, 2015.

CASTELLS, M. Redes de Indignação e Esperança. Movimentos Sociais na Era da Internet. Zahar, 2014.

CESARINO, L. Pós-verdade uma explicação cibernética. VII Reunião de Antropologia da Ciência e da Tecnologia, 2019.

CHAKRABARTY，D. O clima da história: quatro teses. Sopro 91, 2009. Disponível em: http://www.culturaebarbarie.org/sopro/ n91s.pdf acesso 25/01/2021.
CRUTZEN, P.; STOERMER, E. F. The Anthropocene. IGBP, Newsletter, 41, 2000 .

DASTON, L. Beyond Representation. In: COOPMANS, C.; VERTESI, J.; LYNCH, M.; WOOLGAR, S. (eds). Representation in Scientific Practice Revisited. Cambridge, Massachusetts, The MIT, p.319-322, 2014.

DAGNINO, R. Neutralidade da Ciência e Determinismo Tecnológico. Campinas, Editora UNICAMP, 2008.

HARAWAY, D. 'Staying with the Trouble': Making Kin in teh Chthulucence. Duke University Press, 2016.

HAYES, D. Rays of Hope: The Transition to a Post-Petroleum World (New York: W. W. Norton, 1977.

EDWARDS, P.; BOWKER, G. C.; JACKSON, S.; WILLIAMS, R. Introduction: An Agenda for Infrastructure Studies. Journal of Association for Information Systems, p.365-374, 2009.

EVANGELISTA, R. Traidores do movimento: política, cultura, ideologia e trabalho no software livre. Tese (doutorado) Universidade Estadual de Campinas, Instituto de Filosofia e Ciencias Humanas, Campinas, SP, 2010.

FONSECA, C.; ROHDEN, F.; MACHADO, S.; P.; PAIM, S.; H. Antropologia da Ciência e da Tecnologia. Dobras reflexivas. Editora Sulina. 2019.

FOUCAULT, M. Vigiar e Punir. Nascimento da Prisão. Editora Vozes, Petrópolis, 1999. 
HARVEY, P. H.; KNOX, H. Roads: An Anthropology of Infrastructure and Expertise. Cornell University Press, 2015.

HARVEY, P. H.; JENSEN, B. C.; MORITA, A. Infrastructure and Social Complexity: a companion. Routledge, London, and New York, 2017.

HETHERINGTON, K. (ed.). Infrastructure, Environment, and Life in the Anthropocene. Duke University Press, 2019.

HEY, T.; TANSLEY, S.; TOLLE, K. (eds.) The Fourth Paradigm: Data Intensive Scientific Discovery. Edmond, Washington, Microsoft Research, 2009.

HINE, C. (ed.). New Infrastructures for Knowledge Production: Understanding EScience, London, Information Science Publishing. 2006

HUGHES, T. Networks of Power: Electrification of Western Society, 18801930. Baltimore, Johns Hopkins University Press, 1983.

JACKSON, S. J.; EDWARDS, P.; BOWKER， G.; KNOBEL， C. P.; Understanding Infrastructures: History, Heuristics, and Cyberinfrastrutures Policy. First Monday, (12)6, 2007.

JENSEN, C. B.; MORITA, A. Infrastructures as Ontological Experiments. Engaging Science, Technology, and Society (1), p. 81-87. 2015.

JENSEN, B.J; WINTHEREIK, B.R. Monitoring in Development Aid: Recursive Partnerships and
Infrastructures. Cambridge, Massachusetts, The MIT Press, 2013.

JORDAN, T.; TAYLOR, P. A. Hacktivism and cyberwars. Rebels with a cause? Routledge, 2004.

KALPOKAS, I. A Political Theory of PostTruth. Palgrave, 2018.

LATOUR, B. WOOLGAR, S. Vida de laboratório. A produção dos fatos científicos. Relume Dumará, 1997.

LATOUR, B. Visualisation and Cognition: Drawing Things Together. In: H. KUKLICK, H. (ed.). Knowledge and Society Studies in the Sociology of Culture Past and Present, Jai Press vol. 6, pp. 1-40, 1986.

LATOUR, B. Science in Action: How to Follow Scientists and Engineers Through Society. Harvard University Press, 1987.

LATOUR, B. Jamais fomos modernos. Editora 34, 1991.

LATOUR, B. Reagregando o Social. Uma introdução à Teoria do Ator-Rede. Bauru, SP, EDUSC, 2012.

LENHARD, J.; KUPPERS, G.; SHINN, T. (Eds.). Simulation. Pragmatic Construction of Reality. Dordrecht, Netherlands, Springer, p.79-88, 2006.

LEVY, P. Cibercultura. Editora 34, 2010.

LYNCH, M.; WOOLGAR, S. (Eds.). Representation in Scientific Practice. Massachusetts, The MIT Press, 1990.

KNORR-CETINA, K. Epistemic Cultures: How the Sciences Make Knowledge. Massachusetts, Harvard University Press, 1999. 
NEVES, F. M. A contextualização da verdade ou como a ciência torna-se periférica. Civitas Revista de Ciências Sociais, (14)3, p.556-574, 2014.

MARX, K.; ENGELS, F. A Ideologia Alemã. Martins Fontes, 2010.

MIGUEL, J. Infraestruturas e Políticas das Ciências Atmosféricas: Um estudo social da modelagem climática no INPE. Tese de doutoramento. Pós-graduação em Política Científica e Tecnológica, IG UNICAMP, 2017.

MIGUEL, J.; MAHONY, M.; MONTEIRO, M. S. A. Infrastructural geopolitics- of climate knowledge: the Brazilian Earth System Model and the North-South knowledge divide. Sociologias (UFRGS), v. 21, p. 44-75, 2019.

MIGUEL, J.; TADDEI, R.; FIGUEIREDO, F. Coronavirus, infrastructures and sociotechnical (dis)entanglements in Brazil. Social Science \& Humanities, (no prelo).

O'NEIL, C. Weapons of Math Destruction. Crown Books, 2016.

PEREIRA, AD. Apartheid: apogeu e crise do regime racista na África do Sul (1948 1994). In: MACEDO, JR., org. Desvendando a história da África [online]. Porto Alegre: Editora da UFRGS, 2008.

PICKERING, A. (ed.) Science as Practice and Culture. Chicago, University of Chicago Press, 1992.

SISMONDO, S. An Introduction to Science and Technology Studies. Blackwell Publishing, Second Edition, 2010.
SILVEIRA, A. Tudo sobre Tod@s. Redes digitais, privacidade e venda de dados pessoais. Edições, SESC. 2017.

STAR, S. L.; RUHLEDER, K. Steps toward an ecology of infrastructures: Design and access for large information spaces. Information Systems Research, 7(1), p. 111-134, 1996.

STENGERS, I. No tempo das catástrofes. Cosac \& Naify, 2015.

TSING, A. The Mushroom at the End of the World: On the possibility of life in capitalism ruins. Princeton University Press, 2015.

TURKLE, S. The Second Self: computers and the human spirit. The MIT Press, 2005.

WINNER, L. "Do Artifacts Have Politics?" In: WINNER, L. "The Whale and the Reactor - A Search for Limits in an Age of High Technology". Chicago: The University of Chicago Press, p. 19-39, 1986.

WOOLGAR, S.(ed.). Virtual Society? Technology, Cyberbole, Reality. Oxford, Oxford Press, 2002.

WOOLGAR, S.; COOPMANS, C. Virtual Witnessing in a Virtual Age: A prospectus for Social Studies of $\mathrm{E}$ Science. In: HINE, C. (ed.). New Infrastructures for Knowledge Production: Understanding E-Science, London, Information Science Publishing. p.01-25, 2006.

WOOLGAR, S. (eds). Representation in Scientific Practice Revisited. Cambridge, Massachusetts, The MIT, p.319-322, 2014 